\title{
2-Aminobenzimidazole Organocatalyzed Asymmetric Amination of Cyclic 1,3-Dicarbonyl Compounds
}

\author{
Paz Trillo \\ Melania Gómez-Martínez \\ Diego A. Alonso \\ Alejandro Baeza* \\ Departamento de Química Orgánica, Facultad de Ciencias, and Instituto de \\ Síntesis Orgánica (ISO), Universidad de Alicante, Apdo 99, 03080 Alicante, \\ Spain \\ alex.baeza@ua.es
}

Dedicated to the memory of Prof. Carlos F. Barbas III
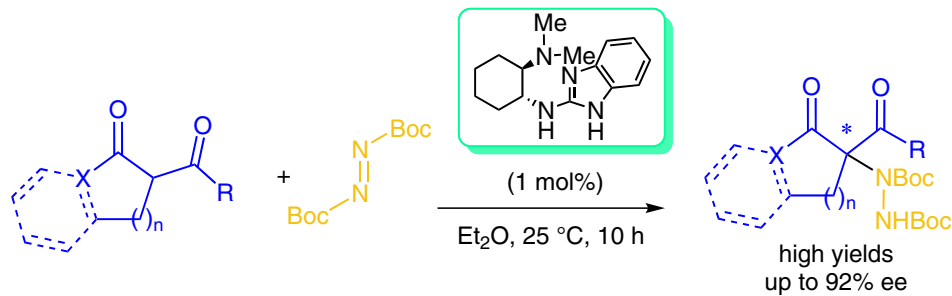

Received: 19.09.2014

Accepted after revision: 18.10 .2014

Published online: 27.11 .2014

DOI: 10.1055/s-0034-1379494; Art ID: st-2014-d0783-I

Abstract The use of a trans-cyclohexanediamine benzimidazole derivative as a hydrogen-bond catalyst for the electrophilic amination of cyclic 1,3-dicarbonyl compounds is herein presented. High yields and enantioselectivities varying from moderate to excellent are generally obtained using mild reaction conditions and as low as $1 \mathrm{~mol} \%$ of catalyst loading.

Key words organocatalysis, electrophilic amination, asymmetric catalysis, dicarbonyl compounds, benzimidazole

The construction of chiral quaternary stereocenters bearing an amine moiety represents an important reaction in synthetic organic chemistry due to the range of compounds possessing such a structure in nature, most of them having biological and pharmaceutical activity. ${ }^{1}$ In this sense, a wide variety of methods has been developed to gain access to these motifs. Among them, the asymmetric electrophilic amination of prochiral carbonyl compounds employing diazocarboxylates as nitrogen source is a simple and straightforward method since the latter reagents are bench-stable and readily available. ${ }^{2}$

Particularly interesting is the catalytic asymmetric $\alpha$ amination of prochiral 1,3-dicarbonyl compounds, since the highly functionalized resulting structures can be further transformed and elaborated. ${ }^{1-3}$ In this regard, several strategies have recently been developed to accomplish this transformation. ${ }^{3}$ Thus, since the pioneer work of Jørgensen and co-workers using a copper(II)-box catalytic system ${ }^{4}$ different methods, not only metal-catalyzed, ${ }^{5}$ but also employing organocatalysts ${ }^{6-8}$ have been reported.

Recently, we have been interested in the use of transcyclohexanediamine benzimidazole derivatives as hydrogen-bonding organocatalysts in various organic transformations. ${ }^{9}$ Therefore, we decided to explore the
Table 1 Catalyst Screening

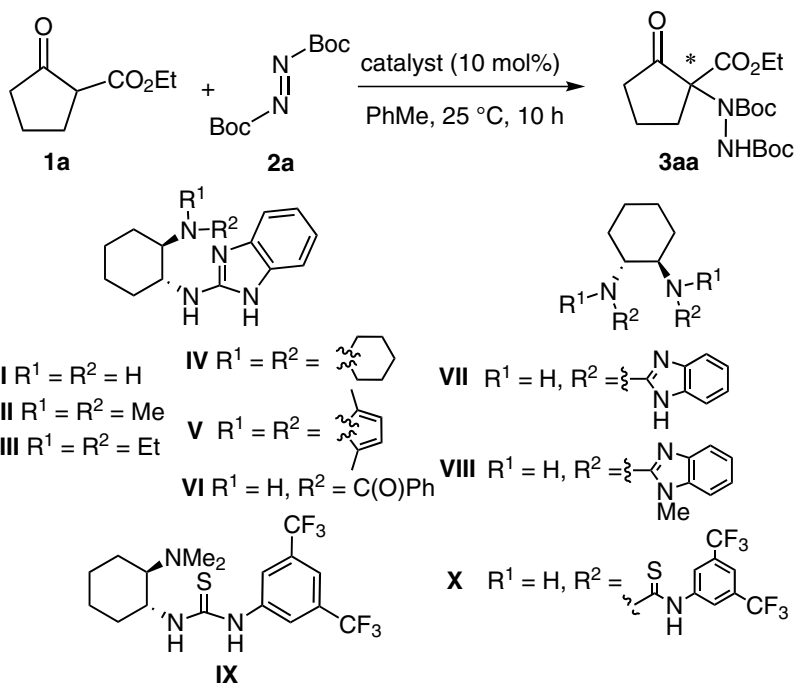

\begin{tabular}{llll}
\hline Entry & Catalyst & ${\text { Conversion }(\%)^{\mathrm{b}}}^{\mathrm{b}}$ & ee (\%) \\
\hline 1 & I & $>95$ & 68 \\
2 & II & $>95$ & 90 \\
3 & III & $>95$ & 75 \\
4 & IV & $>95$ & 85 \\
5 & V & 90 & 10 \\
6 & VI & 80 & rac \\
7 & VII & 90 & 50 \\
8 & VIII & 15 & rac \\
9 & IX & 70 & 65 \\
10 & X & $<15$ & n.d. \\
\hline
\end{tabular}

${ }^{a}$ Reaction conditions: $\mathbf{1 a}(0.10 \mathrm{mmol}), \mathbf{2 a}(0.15 \mathrm{mmol})$, catalyst (10 mol\%) in toluene $(1 \mathrm{~mL})$.

${ }^{b}$ Determined by ${ }^{1} \mathrm{H}$ NMR analysis from the reaction crude.

' Determined by chiral HPLC (Daicel Chiralpak IA, see Supporting Information for details). 
performance of these catalysts in the electrophilic amination of 1,3-dicarbonyl compounds. The results of this study are disclosed herein.

First, the search for the appropriate catalyst to carry out this reaction was tackled using ethyl 2-oxocyclopentanecarboxylate (1a) and di-tert-butylazodicarboxylate (2a) as model substrates (Table 1) and different trans-cyclohexanediamine benzimidazole derivatives I-VIII (Table 1, entries 1-8). The more basic catalysts I-IV afforded the corresponding amination product 3aa in high conversions and enantioselectivities (Table 1, entries 1-4), reaching up to $90 \%$ ee in the case of dimethylamino derivative II (Table 1, entry 2). The presence of less basic nitrogen in the catalysts, as is the case of $\mathbf{V}$ and $\mathbf{V I}$, resulted in a dramatic drop of enantioselection (Table 1, entries 5 and 6). Next, bis(2-aminobenzoimidazole) derivatives VII and VIII were also evaluated, but poorer results were observed in both conversion and enantioselectivity (Table 1, entries 7 and 8). Finally, for the sake of comparison, Takemoto's thiourea catalyst IX and the bisthiourea $\mathbf{X}$ were also evaluated but moderate conversion and enantioselectivity and low conversion were observed, respectively (Table 1, entries 9 and 10)

Once the organocatalyst screening revealed that benzimidazole II provided the best results, further optimization of reaction conditions was performed (Table 2). Firstly, different solvents were tested (Table 2, entries 1-7) obtaining the best results in terms of both conversion and enantioselectivity when toluene, diethyl ether and hexane were employed (Table 2, entries 1, 3 and 6). With these solvents the temperature influence was evaluated. Thus, at $0{ }^{\circ} \mathrm{C}$, the same results were observed (Table 2, entries $8-10$ ) and lowering the temperature to $-20{ }^{\circ} \mathrm{C}$ resulted in lower conversions with enantioselectivity remaining the same. At this point, and since the influence of the temperature was negligible, we decided to continue the optimization at room temperature, using diethyl ether as solvent for solubility reasons. For substrate efficiency, we carried out the reaction using 1.05 equivalents of $\mathbf{2 a}$ and the same results were observed (Table 2, entry 11). Next, the effect of concentration of 1a was studied, and exactly the same results were obtained using $0.2 \mathrm{M}$ and $0.05 \mathrm{M}$ reaction solutions (Table 2, entries 12 and 13); therefore we chose the latter as optimal concentration. Finally, we tried to reduce the amount of catalyst and we observed that not only $5 \mathrm{~mol} \%$ (Table 2, entry 14), but also as low as $1 \mathrm{~mol} \%$ of catalyst loading was enough to promote the reaction with full conversion and excellent enantioselectivity (Table 2, entry 15).

Then, with the optimal reaction conditions established (Table 2, entry 15), we decided to study the influence of the diazocarboxylate structure (Scheme 1 ). Thus, $\beta$-keto ester 1a was allowed to react with different alkyl diazocarboxylates $\mathbf{2 b}$-d but in all cases the results turned out to be worse than that in the case of $\mathbf{2 a}$.
Table 2 Optimization of Reaction Parameters ${ }^{\mathrm{a}}$

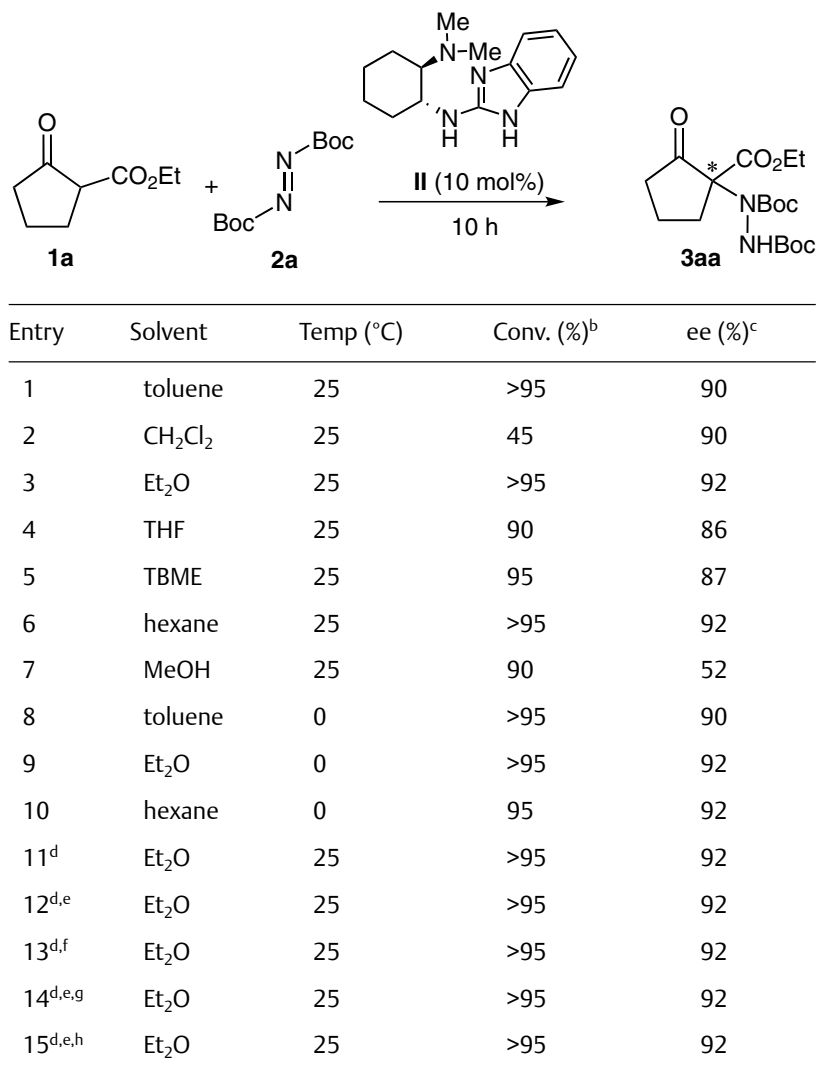

a Reaction conditions: 1 a $(0.10 \mathrm{mmol}), 2$ a $(0.15 \mathrm{mmol})$, II (10 mol\%) in solvent $(1.0 \mathrm{~mL})$.

${ }^{b}$ Determined by ${ }^{1} \mathrm{H}$ NMR analysis from the reaction crude.

c Determined by chiral HPLC (Daicel Chiralpak IA, see Supporting Information for details).

${ }^{\mathrm{d}}$ Amount of $2 \mathrm{a}$ used was $0.105 \mathrm{mmol}$ ( 1.05 equiv).

e Volume of $\mathrm{Et}_{2} \mathrm{O}([\mathbf{1} \mathrm{a}]=0.2 \mathrm{M})$ used was $0.5 \mathrm{~mL}$.

${ }^{f}$ Volume of $\mathrm{Et}_{2} \mathrm{O}([\mathbf{1} \mathbf{a}]=0.05 \mathrm{M})$ used was $2 \mathrm{~mL}$.

g Conditions: 5 mol\% of II, $0.5 \mathrm{~mL}$ of $\mathrm{Et}_{2} \mathrm{O}$.

${ }^{\text {h }}$ Conditions: 1 mol\% of II, $0.5 \mathrm{~mL}$ of $\mathrm{Et}_{2} \mathrm{O}$.

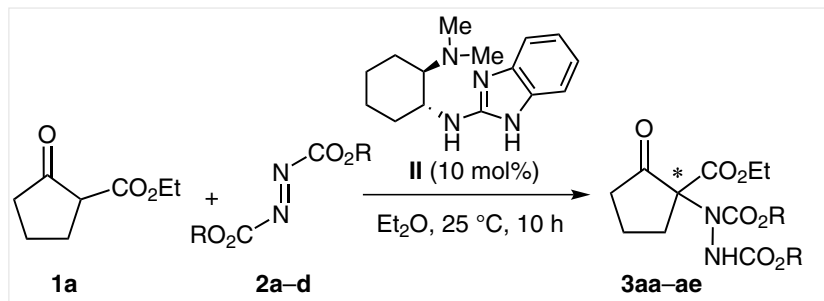

$$
\begin{aligned}
& \text { 2a } \mathrm{R}=t-\mathrm{Bu} \\
& \text { 2b } \mathrm{R}=\mathrm{Bn} \\
& \text { 2c } \mathrm{R}=\mathrm{Et} \\
& \text { 2d } \mathrm{R}=i-\mathrm{Pr}
\end{aligned}
$$

3aa $>95 \%$ conv., $92 \%$ ee 3ab $25 \%$ conv., $74 \%$ ee 3ac $>95 \%$ conv., $74 \%$ ee 3ad $>95 \%$ conv., $80 \%$ ee

Scheme 1 Study of different diazocarboxylates

With the reaction parameters optimized we next explored substrate scope (Table 3$).{ }^{10}$ First, cyclic $\beta$-keto esters were examined. As previously noted 1a yielded the desired 
product in high yields and with 92\% ee (Table 3, entry 1 ). Surprisingly, when the six-membered analogue was submitted to the optimal reaction conditions it failed completely, even when higher catalyst loadings were investigated (Table 3, entry 2). The use of benzocondensed substrate 1c rendered the amination product 3ca in high yield and moderate enantioselectivity (Table 3, entry 3). In contrast, high optical purity along with high yield were obtained with keto ester 1d (Table 3, entry 4). Cyclic $\beta$-amido ester was also examined but a disappointingly low enantioselectivity was obtained despite several reaction conditions tested (Table 3, entry 5).

Next, the more reactive cyclic 1,3-diketones were considered. The five-membered ring diketone 1f was firstly tested obtaining good yield and moderate enantioselectivi- ty (Table 3, entry 6). In this case, the yield was slightly increased by using $5 \mathrm{~mol} \%$ catalyst loading. As already observed in the case of keto esters, the six-membered 1,3diketone $\mathbf{1 g}$ afforded low conversions, regardless of the reaction conditions tested (Table 3, entry 7). The corresponding benzocondensed analogues $\mathbf{1 h}$ and $\mathbf{1 i}$ were also evaluated and, in both cases, gave high yields although moderate enantioselectivities for the corresponding amination products were achieved (Table 3, entry 7 ). In both cases a slight increase of the optical purity was observed by lowering the temperature. Finally, compounds $\mathbf{1 j}$ and $\mathbf{1 k}$ gave rise to the corresponding amination products, 3ja and $\mathbf{3 k a}$ respectively, in good yields but with poor ee values.

Table 3 Substrate Scope

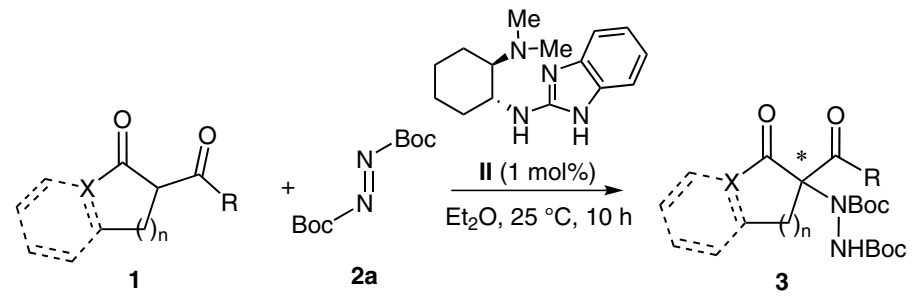

\begin{tabular}{lllll}
\hline Entry & 1 & 3 & Yield (\%) & ee $(\%)^{\mathrm{c}}$ \\
\hline
\end{tabular}

1<smiles>CCOC(=O)C1C[Te]CC1=O</smiles>

$1 \mathrm{~b}$<smiles>CCOC(=O)C1Cc2ccccc2C1=O</smiles>

1c

4<smiles>CCOC(=O)C1CCc2ccccc2C1=O</smiles>

99

92 


\begin{tabular}{|c|c|c|c|c|}
\hline Entry & 1 & 3 & Yield (\%) & ee $(\%)^{c}$ \\
\hline 6 & & $3 f a$ & $75(82)^{d}$ & 50 \\
\hline 7 & & $3 g a$ & $<10$ & n.d. \\
\hline 8 & & 3ha & $88(70)^{\mathrm{e}}$ & $27(35)^{\mathrm{e}}$ \\
\hline 9 & & 3ia & $70(68)^{f}$ & $48(54)^{f}$ \\
\hline 10 & & 3ja & 66 & 26 \\
\hline 11 & & 3ka & 89 & 25 \\
\hline
\end{tabular}

a Unless otherwise stated, the reaction conditions were: $1 \mathbf{a}(0.20 \mathrm{mmol}), \mathbf{2 a}(0.21 \mathrm{mmol}), \mathbf{I l}(1 \mathrm{~mol} \%)$ in $\mathrm{Et}_{2} \mathrm{O}(1 \mathrm{~mL}), 25^{\circ} \mathrm{C}$.

b Isolated yield after column chromatography.

' Determined by chiral HPLC (see Supporting Information for details).

${ }^{\mathrm{d}}$ The reaction was carried out using $5 \mathrm{~mol} \%$ of II.

e The reaction was carried out at $-20^{\circ} \mathrm{C}$.

${ }^{f}$ The reaction was carried out at $-50^{\circ} \mathrm{C}$.

Different linear $\beta$-keto ester and 1,3-diketones were also evaluated but, despite our efforts, racemic mixtures were obtained in all the cases.

Regarding the reaction mechanism, and based on previous computational and experimental studies carried out by our research group employing identical catalysts for the asymmetric conjugate addition of 1,3-dicarbonyl compounds onto nitroalkenes, ${ }^{\text {aa }}$ we propose the catalytic cycle depicted in Scheme 2 in which benzimidazole II can act as a bifunctional organocatalyst. Thus, II can act initially as a base, forming the corresponding 1,3-dicarbonyl compound enolate, that can coordinate through hydrogen-bonding to the catalyst, as depicted in intermediate $\mathbf{A}$. Then, the protonated dimethylamino moiety can activate the diazocarboxylate and hence facilitate the enantioselective attack of the enolate (intermediate $\mathrm{B}$ ), releasing the corresponding amination product and regenerating the organocatalyst II.
It is worthy of note that the $S$-configured amination product seems to be obtained when $(R, R)$-II is employed. This assumption was taken from a specific rotation comparison between product 3aa and the values reported in literature. ${ }^{11}$

In conclusion, we have demonstrated that chiral transcyclohexanediamine benzimidazole derivative II is a suitable and effective organocatalyst for the asymmetric electrophilic amination of cyclic 1,3-dicarbonyl compounds. The corresponding amination products are obtained in the majority of the cases with high yields and moderate to high enantioselectivities using just $1 \mathrm{~mol} \%$ of catalyst loading. In addition, a bifunctional role of the catalyst is assumed due to a presumably dual hydrogen-bond activation of both the 1,3-dicarbonyl compound and the diazocarboxylate. 

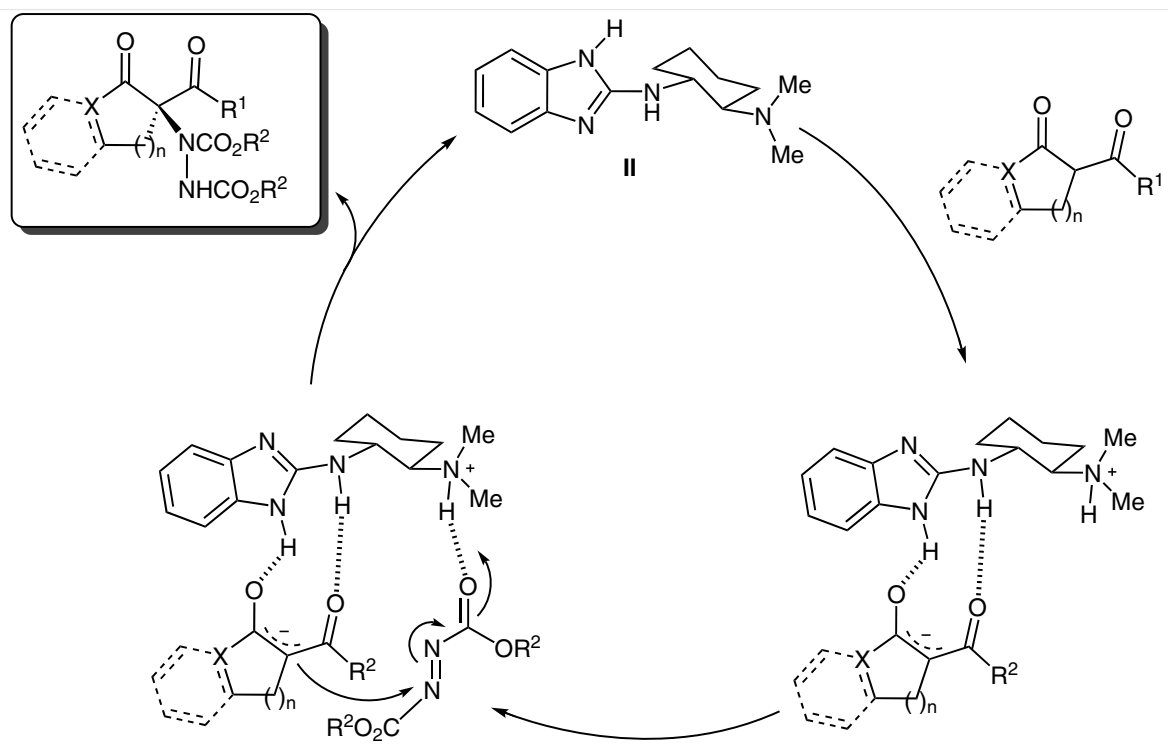

B<smiles>[R]OC(=O)N=NC(=O)O</smiles>

A

Scheme 2 Proposed catalytic cycle

\section{Acknowledgment}

Financial support from the University of Alicante (VIGROB-173, GRE12-03, UAUSTI13-01, UAUSTI13-02) is gratefully acknowledged.

\section{Supporting Information}

Supporting information for this article is available online at http://dx.doi.org/10.1055/s-0034-1379494.

\section{References}

(1) (a) Broggini, G.; Borsini, E.; Piarulli, U. In Science of Synthesis, Cross-Coupling and Heck-Type Reactions; Vol. 3; Molander, G. A.; Wolfe, J. P.; Larhed, M., Eds.; Thieme: Stuttgart, 2013, 521-583. (b) Christoffers, J.; Mann, A. Angew. Chem. Int. Ed. 2001, 40, 4591. (c) Corey, E. J.; Guzman-Perez, A. Angew. Chem. Int. Ed. 1998, 37, 389.

(2) Ciganek, E. In Organic Reactions; Vol. 72; Denmark, S. E., Ed.; Wiley: New Jersey, 2008, 1-366.

(3) For selected reviews about electrophilic amination, see: (a) Erdik, E. Tetrahedron 2004, 60, 8747. (b) Greck, C.; Drouillat, B.; Thomassigny, C. Eur. J. Org. 2004, 1377. (c) Guillena, G.; Ramón, D. J. Tetrahedron: Asymmetry 2006, 17, 1465. (d) Vilaivan, T.; Bhanthumnavin, W. Molecules 2010, 15, 917. (e) Vallribera, A.; Sebastian, R. M.; Shafir, A. Curr. Org. Chem. 2011, 15, 1539. (f) Russo, A.; De Fusco, C.; Lattanzi, A. RSC. Adv. 2012, 2, 385. (g) Chauhan, P.; Chimni, S. S. Tetrahedron: Asymmetry 2013, 24, 343.

(4) Marigo, M.; Juhl, K.; Jørgensen, K. A. Angew. Chem. Int. Ed. 2003, $42,1367$.
(5) For selected examples of metal-catalyzed electrophilic amination of 1,3-dicarbonyl compounds with diazocarboxylates, see: (a) Foltz, C.; Stecker, B.; Marconi, G.; Bellemin-Laponaz, S.; Wadepohl, H.; Gade, L. H. Chem. Commun. 2005, 5115. (b) Kang, Y. K.; Kim, D. Y. Tetrahedron Lett. 2006, 47, 4565. (c) Mashiko, T.; Kumagai, N.; Shibasaki, M. J. Am. Chem. Soc. 2009, 131, 14990. (d) Mang, J. Y.; Kwon, D. G.; Kim, D. Y. Bull. Korean Chem. Soc. 2009, 30, 249. (e) Ghosh, S.; Nandakumar, M. V.; Krautscheid, H.; Schneider, C. Tetrahedron Lett. 2010, 51, 1860. (f) Torres, M.; Maisse-François, A.; Bellemin-Laponaz, S. ChemCatChem 2013, 5,3078 .

(6) For selected examples of electrophilic amination of 1,3-dicarbonyl compounds with diazocarboxylates using chiral amines as organocatalysts, see: (a) Saaby, S.; Bella, M.; Jørgensen, K. A. J. Am. Chem. Soc. 2004, 126, 8120. (b) Pihko, P. M.; Pohjakallio, A. Synlett 2004, 2115. (c) Liu, X.; Li, H.; Deng, L. Org. Lett. 2005, 7, 169. (d) Santacruz, L.; Niembro, S.; Santillana, A.; Shafir, A.; Vallribera, A. New J. Chem. 2014, 38, 636.

(7) For selected examples of electrophilic amination of 1,3-dicarbonyl compounds with diazocarboxylates using phase-transfer catalysts, see: (a) He, R.; Wang, X.; Hashimoto, T.; Maruoka, K. Angew. Chem. Int. Ed. 2008, 47, 9466. (b) Lan, Q.; Wang, X.; He, R.; Ding, C.; Maruoka, K. Tetrahedron Lett. 2009, 50, 3280. (c) He, R.; Maruoka, K. Synthesis 2009, 2289.

(8) For selected examples of electrophilic amination of 1,3-dicarbonyl compounds with diazocarboxylates using hydrogen-bond catalysis, see: (a) Xu, X.; Yabuta, T.; Yuan, P.; Takemoto, Y. Synlett 2006, 137. (b) Terada, M.; Nakano, M.; Ube, H. J. Am. Chem. Soc. 2006, 128, 16044. (c) Jung, S. H.; Kim, D. Y. Tetrahedron Lett. 2008, 49, 5527. (d) Konishi, H.; Lam, T. Y.; Malerich, J. P.; Rawal, V. H. Org. Lett. 2010, 12, 2028. (e) Han, X.; Zhong, F.; Lu, Y. Adv. Synth. Catal. 2010, 352, 2778. (f) Zhang, Z.-H.; Dong, X.-Q.; Tao, H.-Y.; Wang, C.-J. ARKIVOC 2011, (ii), 137. (g) Inokuma, T.; Furukawa, M.; Uno, T.; Suzuki, Y.; Yoshida, K.; 
Yano, Y.; Matsuzaki, K.; Takemoto, Y. Chem. Eur. J. 2011, 17, 10470. (h) Murai, K.; Fukushima, S.; Nakamura, A.; Shimura, M.; Fujioka, H. Tetrahedron 2011, 67, 4862.

(9) For recent publications, see: (a) Almasi, D.; Alonso, D. A.; Gómez-Bengoa, E.; Nájera, C. J. Org. Chem. 2009, 74, 6163. (b) Gómez-Torres, E.; Alonso, D. A.; Gómez-Bengoa, E.; Nájera, C. Org. Lett. 2011, 13, 6106. (c) Gómez-Torres, E.; Alonso, D. A.; Gómez-Bengoa, E.; Nájera, C. Eur. J. Org. Chem. 2013, 1434. (d) Trillo, P.; Baeza, A.; Nájera, C. Synthesis 2014, in press; DOI: 10.1055/s-0034-1378618.

(10) General Procedure for the Asymmetric Amination of Cyclic 1,3-Dicarbonyl Compounds: In a tube, open to the atmosphere, in a thermostated bath $\left(25{ }^{\circ} \mathrm{C}\right)$ the requisite 1,3 -dicarbonyl compound $(0.2 \mathrm{mmol})$ was added to a solution of organocatalyst II $(0.002 \mathrm{mmol}, 1 \mathrm{~mol} \%)$ in $\mathrm{Et}_{2} \mathrm{O}(1 \mathrm{~mL})$. After 5 min, di-tert-butylazodicarboxylate (2a; $0.21 \mathrm{mmol}, 1.05$ equiv) was added in one portion and the reaction was then allowed to react for $10 \mathrm{~h}$. After this time, $\mathrm{H}_{2} \mathrm{O}(5 \mathrm{~mL})$ and EtOAc were added, and then the aqueous layer was re-extracted with EtOAc $(2 \times 5 \mathrm{~mL})$. The combined organic phases were dried $\left(\mathrm{MgSO}_{4}\right)$, filtered and the solvent was evaporated under reduced pressure.
Finally, the crude product was purified by flash chromatography using hexanes-EtOAc mixtures as eluent.

Physical and spectroscopic data given below are for compound 3da and may be taken as representative. For further details; see Supporting Information. Di-tert-butyl 1-[2-(Ethoxycarbonyl)1-oxo-1,2,3,4-tetrahydronaphthalen-2-yl]hydrazine-1,2-

dicarboxylate (3da) $)^{8 \mathrm{~b}}$ Slightly yellow viscous oil (88 mg, 98\% yield, $91 \%$ ee $)$; $[\alpha]_{\mathrm{D}}{ }^{28}+23.3\left(c=2.0, \mathrm{CHCl}_{3}\right) .{ }^{1} \mathrm{H}$ NMR $(300 \mathrm{MHz})$ : $\delta=1.33(\mathrm{br} \mathrm{m}, 21 \mathrm{H}), 2.67(\mathrm{~m}, 1 \mathrm{H}), 2.95(\mathrm{~m}, 2 \mathrm{H}), 3.44$ (br m, 1 H), $4.31(\mathrm{q}, J=7.0 \mathrm{~Hz}, 2 \mathrm{H}), 6.23(\mathrm{~m}, 1 \mathrm{H}), 7.25(\mathrm{~m}, 2 \mathrm{H}), 7.46(\mathrm{~m}$, $1 \mathrm{H}), 7.95$ (dd, $J=28.0,7.2 \mathrm{~Hz}, 1 \mathrm{H}) .{ }^{13} \mathrm{C}$ NMR $(75 \mathrm{MHz}): \delta=14.1$, 25.6, 27.7, 28.0, 31.1, 60.3, 61.9, 80.8, 82.7, 126.4, 127.7, 128.5, 131.7, 133.4, 154.4, 155.5, 169.5, 191.0. MS (IE): $m / z(\%)=348$ (6.5) [ $\mathrm{M}^{+}$- Boc], 292 (47), 219 (100), 175 (86), 158 (30). Chiral HPLC analysis: Chiralcel IA column, hexane- $i$-PrOH (85:15), flow rate $=1 \mathrm{~mL} / \mathrm{min}, \lambda=254 \mathrm{~nm}$, retention times: $t_{R}=8.0,11.5$ $\min$.

(11) (S)-3aa $[\alpha]_{D}^{29}+3.8\left(c=1, \mathrm{CHCl}_{3}, 92 \%\right.$ ee). Reported value in ref. $5 \mathrm{~b}$ for $R$-enantiomer: $[\alpha]_{\mathrm{D}}{ }^{32}-3.47\left(c=1.09, \mathrm{CHCl}_{3}, 97 \%\right.$ ee $)$. See Supporting Information for further details. 